Annals of Plant Sciences

ISSN: 2287-688X

OPEN ACCESS

www.annalsofplantsciences.com

Research Article

\title{
Effect of post-harvest treatment and storage temperature on fragrance of Jasmine ( $J$. grandiflorum)
}

Mohanasundari P.1*, Sivakumar T.1, Krishna Surendar K. ${ }^{1}$ and M. Ganga ${ }^{2}$

${ }^{1}$ Department of Crop Physiology, Tamil Nadu Agricultural University, Coimbatore, 641003, India.

${ }^{2}$ Associate Professor (Horticulture) and Head, TNAU-HRS, Ooty, 643001, India.

Received: 21-06-2018; Revised: 29-06-2018; Accepted: 19-07-2018

\begin{abstract}
The postharvest experiment was conducted to maximize the shelf life of Jasminum grandiflorum without losing its fragrance using with different chemical solution in department of Crop Physiology, Tamilnadu Agricultural University during 2017 - 2018. The demand for this species for oil extraction is more compared to other species. Among the Jasmine flower production major quantity of Jasmine flowers are utilized for isolating and manufacturing Jasmine oils. The experimental design followed for this study is FCRD. The chemical solutions viz., silver nano particle

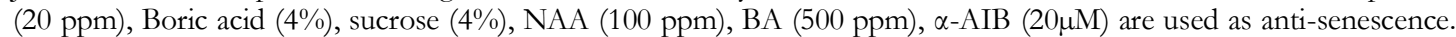
After chemical treatment the flower buds packed in polypropylene bags (200 gauges) and stored in ambient and cold storage condition. The observation was made periodically up to flower senescence. Among the different chemical treatment silver nano-particle $(20 \mathrm{ppm})$ having the significant effect on fragrance and shelf life over control.
\end{abstract}

Keywords: Jasminum grandiflorum, Fragrance. Shelf life, Storage, Post-harvest treatment

\section{Introduction}

Jasmine is an important fragrant flowers used from very ancient period. Buds and opened flowers are used for making garlands and bouquets for various purpose. In Tamilnadu and UP these flowers are used for production of perfumed hair oils. Large quantity utilized for isolating and manufacturing jasmine oils in Europe and Mediterranean Countries. Its unique odor can't be imitated by a mixture of any known synthetic aromatic chemicals and natural isolates.

The discovery of the invention structure of jasmine ketone as now brought the estimation of the common smell by blend a stage close up. On the off chance that the present high flavor consistent, aromas will be contended to way out an ever increasing number of manufactured substitutes and in result, a dropping off in the importance for the normal item may happen. India is a noteworthy maker of Jasmine, of which 80 percent is acknowledged from Tamil Nadu. Disregarding this, the Indian Jasmine producers' don't give off an impression of being a sure part. It is essential that Government of India ought to consider the fare arranged Jasmine Industry as a thrust region for development and support.

Jasmine constitutes a gathering of fragrant blossoms which are monetarily developed all through the nation over a region of around 8000 hectares. Jasmines contribute significantly to the national economy, and every year about Rs. 20 crores worth of blooms is deliver in India.

*Corresponding Author:

Ms. P. Mohanasundari,

Research Scholar,

Department of Crop Physiology,

TNAU, Coimbatore-3, India.

E-mail: mohanasundari612@gmail.com
Tamil Nadu is the leading state in the India for production and export of Jasmine flower bud. Fresh flower buds are delivered for inside exchange and furthermore for fare to the neighboring nations like Srilanka, Singapore, Malaysia and to the Gulf nations.

The family Jasminum is accounted for to include around 200 species. A basic investigation of this species uncovered the quantity of genuine species to be just 89 of which 40 occupy in the Indian sublandmass. In South India, huge amounts of Jasmine blossoms are utilized by ladies society for adorn their hair. The blossoms are additionally utilized for the manufacture of scents and attars. The world renowned Jasmine Oil is extricated from the blooms of Spanish Jasmine (Jasminum grandiflorum). The Jasmine oil is viewed as one of a kind as it mixes well with botanical concentrates and it is exceedingly esteemed all through the world for creating high review scents. The oil finds the place in cleanser and restorative businesses too.

In countries like Japan, the U.K., USA, USSR, Scandinavia, East Europe etc., there is a growing demand for spirituous perfumes and colognes during recent past years. In India it still produces attars and non-spirituous perfumes by traditional method so it lost its leading position as a perfume producer because of it. It is thus apparent that there is a good scope for large scale development of spirituous perfume based on Jasmine for export purpose. Based on the above constraints the present 
study focused on to increase the shelf life by using various chemical treatments without affecting the fragrance of flowers.

\section{Materials and Methods}

The experiment was carried out at the department of Crop Physiology, Tamil Nadu Agricultural University, and Coimbatore. The experiment design followed for this study is FCRD and each treatment replicated as thrice. The treatments comprised of six anti-senescence chemicals viz., Silver nano particle (20 ppm), Boric acid (4\%), Sucrose (4\%), NAA (100 ppm), BA (500ppm), $\alpha$-Amino isobutyric acid $(20 \mu \mathrm{M})$ and control. The flowers were harvested at morning time between 6.30 to 7.30 . Harvested flower buds then immersed in chemical solution by quick dipping method and surface drying was done. After that it was packed in 200 gauge polypropylene bag with no ventilation then stored in cold storage and ambient storage condition. Different physiological and biochemical parameters were taken up at three different stages viz., bud stage, open stage and senescence stage.

Fragrance index was measured by hand held e-nose system.10g of jasmine flower (Jasminum grandiflorum) sample were tested under handheld e-nose system (HEN) developed by TNAU, Coimbatore and Centre For Development Of Advanced Computing (C-DAC), Kolkata, which produce a fragrance index of tested samples. The Mos sensors (Metal oxide sensors) react to volatile compounds on contact; the absorption of volatile compounds on the sensors surface causes a physical change of the sensor. The generation of aroma volatiles from the sample is called headspace. Fixed air pressure is generated in the air-tight sample chamber to generate aroma volatiles. Sampling is the process in which the aroma volatiles generated during headspace are exposed to the sensor array in a controlled manner so as to maintain a constant operating condition all the time. A valve is made open and kept open for a fixed time so that aroma volatiles generated inside the sample holder may move to the sensor chamber at a fixed flow rate over a fixed period. During this entire period, changes on the electrical properties of all the sensors are recorded for analysis.

\section{Statistical analysis}

Statistical analysis for the Factorial Complete Randomized Block Design (FCRD) viz., computation of mean, standard error, and critical difference was carried out using Excel and SPSS 9.4 packages. The required graphs were drawn using MS Excel software packages. The per cent values were first transformed to angular arcsine values before the analysis wherever it necessary. The data were tested for at five per cent level $\left(^{*}\right)$ and one per cent level (**) for significance and non-significant (NS). Wherever the treatment differences were found significant (' $\mathrm{F}$ ' test) critical differences were worked out at five per cent probability level and the values furnished. Differences between the treatments were determined using Duncan's test.

\section{Results and Discussion}

Observations were recorded on the bud stage, open stage and senescence stage after imposition of treatments. The recorded observations are pursued in tables.

Table 1. Storage room condition

\begin{tabular}{ccc}
\hline Storage Condition & Temperature $\left({ }^{\mathbf{0}} \mathbf{C}\right)$ & RH (\%) \\
\hline Cold & $6-7$ & $85-95$ \\
Ambient & $20-22 \pm 2$ & $60-75$ \\
\hline
\end{tabular}

The data is conferred that the significant difference was observed among the treatments, storage and treatment storage interaction with respect to fragrance index and shelf life.In all the recorded parameters SNP maintain height values in cold storage condition and NAA maintain highest values in case of ambient storage conditions. Flower fragrance is a fundamental character which is controlled by genetically controlled factor. Though it being a genetic character, varied among the treatments while treated with chemicals and stored in different condition.

Figure 1. Effect of different post-harvest treatment on fragrance index of J.grandiflorum under ambient storage condition

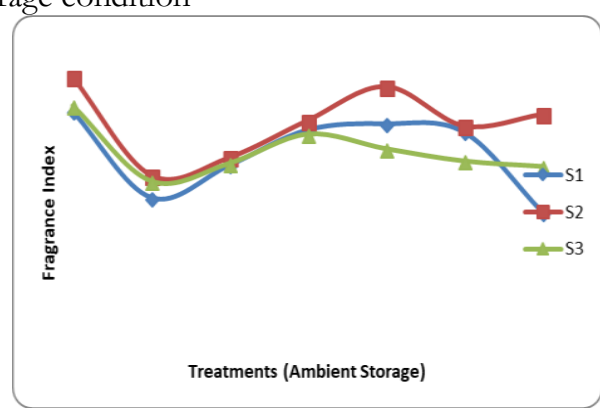

S1- Bud stage; S2- Opening stage; S3- Senescence Stage

Figure 2. Effect of different post-harvest treatment on fragrance index of J.grandiflorum under cold storage condition

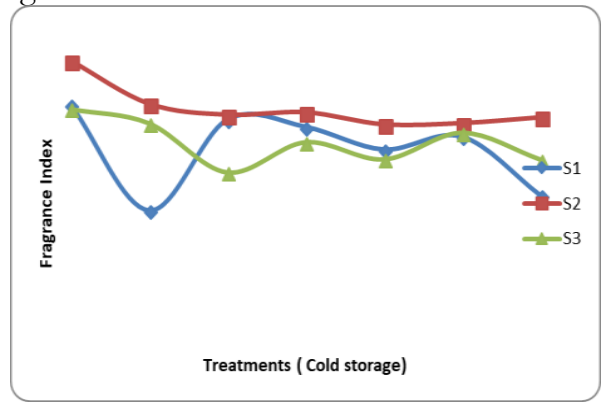

S1- Bud stage; S2- Opening stage; S3- Senescence Stage

There is a significant difference observed among the treatments in fragrance index at bud, open and senescence stages. This effect may be influenced by treatment, storage and package. Highest fragrance 
index recorded in control at all the three stages in both the storage condition. In bud stage control recorded highest fragrance index (35.1) but the treatment boric acid also having on par with control recorded fragrance index (33.2) in cold storage and NAA (32.9) in ambient storage condition. Least index was recorded in the treatment of SNP (21.6) stored in cold condition. In interaction effect also control and boric acid had a significant effect on fragrance index.

During flower opening stage and senescence stage control recorded highest $(40.7$; 34.6) fragrance index followed by SNP $(35.2 ; 32.8)$ in cold storage and NAA $(38.8 ; 30.7)$ in ambient condition. The least fragrant index observed in NAA (32.6) and sucrose (26.4) stored in cold storage and SNP (27.3; $26.5)$ stored in cold storage condition at opening and senescence stage respectively.

Based on the respiration rate the fragrance index varies with different treatment. The fragrance index will be increased towards flower opening and then it gets declined at senescence stage, at this stage fragrance turn into undesirable quickly due to buildup of more $\mathrm{CO}_{2}$ concentration and trivial amount of $\mathrm{O}_{2}$.

Flowers stored in ambient condition recorded higher fragrance index without any treatment. This may be due to the non-chemical effects and more respiration rate inside the polypropylene bag might create a modified atmosphere that leads to increase the fragrance index. The respiration rate maintained up to flower opening stage under cold room condition that might be affecting the fragrance index. the same finding was reported by Thamarai selvi et al., (2009), who observed that Jasminum grandiflorum, J.sambac and Polianthus tuberosa packed in different packing material and stored in ambient and cold room condition cause undesirable odour after losing the shelf life of those flowers.

However in both the storage condition increasing $\mathrm{CO}_{2}$ level and decreasing $\mathrm{O}_{2}$ cause anaerobic respiration subsequently it cause the emission of undesirable fragrance during senescence stage. Cameron et al., (1995), Smyth et al., (1998) supported this finding, they reported broccoli, and lettuce etc of cut products packed in packaging material. Its might cause odour inside the package.
High level concentration of $\mathrm{CO}_{2}$ and $\mathrm{O}_{2}$ can stimulate the fermentation and cause formation of undesirable flavours (Song et al., 1997, Ferny 2001). Many fruits and vegetable that are held in MAP cause changes in their original flavours.

\section{Conclusion}

Even though control registered a maximum value but it had very minimum shelf life as one day. Our aim is to enhance the flower longevity without much affecting the fragrance. The present study found that the flower bud treated with SNP registered highest shelf life with high fragrance index compared with any other treatments used for this study. It might be much useful for oil extraction industry during the peak period of flowering.

\section{References}

1. Cameron, A.C., Talasila, P.C. and Joles, D.W., Predicting film permeability needs modified atmosphere packaging of lightly processed fruits and vegetables. Horti. Sci., 30-1 (1995): 25-34.

2. Forny, C.F., Horticultural and other factors affecting aroma volatile composition of small fruit. Horti. Technol., 114 (2001): 529-538.

3. Smyth, A.B., Song, J. and Cameron, A.C., Modified atmosphere packaged cut iceberg lettuce: effect of temperature and $\mathrm{O}_{2}$ partial pressures on respiration and quality. J.Agric.Food chem., 46 (1998): 4556-4562.

4. Song, J., Deng, W., Fan, L., Verschoor, J. and Beauty, R., Aroma volatiles and quality changes in modified atmosphere packaging. Pp. 89-95. In: J. Gorny (ed), Proc. 7th Intl. Controlled Atmosphere Conf. Vol.5. Fresh cut fruits, vegetables and MAP.Univ. Calif.Post harvest Horti.ser. 19 (1997).

5. Thamarai selvi, S.P., Jawaharlal, M., Standardization of export technology for packaging technology for jasmine and tuberose. PhD Thesis, 2009.Tamilnadu Agricultural University.

\section{Cite this article as:}

Mohanasundari P., T. Sivakumar, K. Krishna Surendar, M. Ganga. Effect of post-harvest treatment and storage temperature on fragrance of Jasmine (J. grandiflorum). Annals of Plant Sciences 7.8 (2018) pp. 2391-2393.

do http://dx.doi.org/10.21746/aps.2018.7.8.4 